\title{
Mudança de estrutura organizacional e serviços prestados: análise numa instituição federal de ensino superior do Nordeste.
}

Ana Beatriz de Medeiros Regsis Ferreira - http://orcid.org/00000002-4345-1595 - bia.mr9104@gmail.com ${ }^{1}$ Yákara Vasconcelos Pereira - http://orcid.org/0000-0003-0865-6170 - yakarav@gmail.com² Karla Rosane do Amaral Demoly - http://orcid.org/00000002-1727-9875 - karla.demoly@gmail.com ${ }^{1}$

Resumo - A Universidade Federal Rural do Semi-Árido (UFERSA), instituição pública federal de ensino superior prestadora de serviços educacionais, passou por um processo de mudança organizacional quando implementou novo Estatuto, o que implicou em transformações na estrutura organizacional. Diante desse contexto, esta pesquisa teve o objetivo de analisar a relação entre a mudança de estrutura organizacional da UFERSA motivada pela implementação do novo Estatuto e os serviços prestados. Para tanto, realizou-se estudo de caso qualitativo viabilizado pela coleta de dados por meio de questionários enviados aos gestores, servidores e discentes, totalizando 239 respostas. A pesquisa documental de arquivos públicos compõe a fonte de dados secundários obtida em documentos oficiais da universidade, a saber: portarias; Estatuto Antigo-versão 2013 e Novo Estatuto da UFERSA-versão 2016. Os dados foram examinados por meio da análise de conteúdo.

Palavras-chaves: Mudança organizacional, Serviços, Gestão Pública.

\section{Change of organizational structure and services provided: analysis at a federal institution of higher education in the Northeast.}

\begin{abstract}
The Federal Rural University of the Semi-Arid (UFERSA), a federal public institution of higher education that provides educational services, underwent a process of organizational change when it implemented a new Statute, which implied transformations in the organizational structure. In this context, this research aimed to analyze the relationship between the change in UFERSA's organizational structure motivated by the implementation of the new Statute and the services provided. To this end, a qualitative case study was carried out, made possible by data collection through questionnaires sent to managers, employees and students, totaling 239 responses. The documentary research of public archives makes up the source of secondary data obtained in official university documents (Ordinances; Old Statute-version 2013 and New Statute of UFERSA-version 2016) and the organizational charts proposed in the respective documents. The data were examined through content analysis.
\end{abstract}

Keywords: Organizational change, Services, Public Administration.

Data da Submissão: $24 / 09 / 2020$

Data de aceitação: 17/04/2021

DOI: $10.51359 / 2317-0115.2021 .248370$ 


\section{Introdução}

A sociedade vive em um cenário de constantes mudanças (VIEIRA; VIEIRA, 2003) das mais diversas ordens, as quais implicam no processo de globalização. As transformações fazem com que os antigos modelos de organização fiquem ultrapassados, ineficientes e inapropriados (FREITAS JÚNIOR et al., 2015), o que cria a necessidade de adaptação (AL-DAAJA, 2017) que pode resultar na implementação de processos de estruturação (COSTA; SOUZA; FELL, 2012).

Nesse cenário, as instituições de ensino superior (IES) são organizações prestadoras de serviços, cuja função é formar profissionais qualificados atuantes no mercado de trabalho e/ou em pesquisas científicas (FREITAS JÚNIOR et al., 2015). Ao considerar que as universidades são afetadas "[...] pelas incertezas internas e externas geradas pela globalização" (FREITAS JÚNIOR et al., 2015, p. 2), percebe-se que as organizações com estruturas acadêmicas, enquanto produtoras e propagadoras do conhecimento, devem estar aptas a liderar e acompanhar as transformações contemporâneas (VIEIRA; VIEIRA, 2003).

Para Costa, Souza e Fell (2012, p. 4), a estrutura organizacional reflete o que uma organização determina, portanto "[...] é importante porque nela estão componentes como delegação de poder, processo decisório, comunicação, especialização, participação, centralização e formalismo". O fator crítico está na obsolescência das estruturas organizacionais e modelos de planejamento das universidades, frente às intensas transformações contextuais (LOPES; BERNARDES, 2005). Sobre o assunto, Vieira e Vieira (2003) afirmam que as universidades federais são contraditórias, pois quando deveriam agir no entorno da inovação, flexibilidade e eficiência, passam a ser caracterizadas por suas estruturas antigas, de pouca eficiência e elevada burocratização. Para os autores fica evidente a defasagem da estrutura organizacional da maioria das universidades.

Assim, o modelo burocrático que ainda é seguido por determinadas instituições públicas brasileiras acaba por tornar as estruturas administrativas centralizadas e produz serviços que não correspondem aos novos desafios da sociedade (FREITAS JÚNIOR et al., 2015). Por esse motivo "[...] a universidade pública brasileira vem experimentando profundos questionamentos também no que se refere a sua estrutura, organização e administração, assim como sobre a eficiência e qualidade do seu trabalho, seus serviços” (ESTRADA, 2000, p.2).

No tocante à oferta de serviços, Costa, Souza e Fell (2012) defendem que uma organização que tolera mudanças passa a gerar oportunidades de crescimento, por meio de diferencial, vantagem competitiva e agregação de valor que, juntos, permitem oferecer produtos e serviços diferenciados, proporcionando excelentes resultados. Portanto, o estudo de mudança nas organizações ainda é apontado como relevante e necessita de empenho científico para garantir a continuidade de investigações sobre o tema (JANTUNEN et al., 2018).

Nesse contexto observa-se a Universidade Federal Rural do Semi-Árido (UFERSA), instituição pública federal de ensino superior localizada no interior do Rio Grande do Norte. A UFERSA foi criada no ano de 2006, quando deixou de ser Escola Superior e tornou-se u niversidade. Em 2016, vivenciou importante processo de mudança, quando implementou o novo Estatuto, o que implicou em diversas transformações, inclusive, na estrutura organizacional. Diante do exposto, considerando as mudanças ocorridas na universidade, bem como a relevância dos serviços prestados à sociedade, esta pesquisa tem o objetivo de analisar a relação entre a mudança de estrutura organizacional da UFERSA motivada pela implementação do novo 
Estatuto e os serviços prestados. Para tanto, este artigo subdivide-se no referencial teórico, procedimentos metodológicos da pesquisa, discussão dos resultados e considerações finais.

\section{Gestão de serviços de instituições de ensino superior}

Serviço consiste na atividade em que há o relacionamento entre fornecedor e consumidor, a fim de atender à necessidade do cliente (CAVALCANTI; FONSECA, 2012), situação em que a produção e consumo ocorrem simultaneamente, por meio de processos subjetivos (SPANHOL; FIGUEIREDO NETO; LIMA-FILHO, 2010) que são percebidos conforme aspectos individuais, envolvendo experiência e confiança, dentre outras questões (DINIZ, ROSADAS; MACEDO, 2006). Em complemento ao exposto, Lovelock, Wirtz e Hemzo (2011) defendem que serviços se constituem de um conjunto de elementos tangíveis e, principalmente, intangíveis que são a principal fonte de criação de valor para o usuário, sem que haja apropriação dos elementos tangíveis envolvidos na execução do serviço. Assim, pode-se afirmar que "[...] a educação escolar e/ou universitária insere-se no contexto de uma instituição prestadora de serviços, isto é, de serviços educacionais.” (SPANHOL; FIGUEIREDO NETO; LIMA-FILHO, 2010, p. 67).

Insta menciona que o surgimento das universidades no Brasil ocorreu por volta do século XIX, quando da chegada da família real portuguesa (SANTOS, 2014). Com o passar dos anos, as instituições de ensino superior ganharam mais espaço, em virtude das constantes transformações do mundo que passaram a exigir profissionais cada vez mais capacitados, o que aumentou a procura às universidades, ampliando, consequentemente a competitividade no mercado de serviços educacionais (MAINARDES; DOMINGUES; DESCHAMPS, 2009).

Os serviços educacionais, por sua vez, diferenciam-se dos demais tipos de serviços porque envolvem aspectos particulares, como a relação com o saber e a transformação do indivíduo com base no conhecimento (IOTTI NETO, 2004). Contudo, apesar de suas particularidades, a instituição que desenvolve serviços educacionais é uma organização tal qual as demais no que se refere à finalidade, que compreende atender com qualidade as necessidades do público (MEZOMO, 1994).

Para Resende Júnior (2007), a gestão de serviços está cada vez mais complexa porque tem envolvido diversos aspectos em seus processos, e ainda por conta das transformações que têm exigido níveis de serviços superiores. Contudo, o autor afirma que essas organizações educacionais ainda vêm adotando ações clássicas de gestão de serviços.

Na visão de Floriano et al. (2013), para que se consiga atender expectativas e manter a qualidade dos serviços frente a este cenário, é preciso que haja empenho de gestores e funcionários no processo de gestão, por meio de estratégias adequadas. A referida qualidade, por sua vez, é essencial para a sobrevivência dessas organizações (SANTOS, 2014). E a participação de todos nas diversas etapas deve abranger a estrutura organizacional (MENDONÇA; SELIG; SILVA, 2005).

Para Gianesi e Corrêa (2012), a qualidade ideal dos serviços prestados ocorre quando a percepção do cliente para com o serviço supera as suas expectativas. Assim, na medida em que as expectativas são atendidas, fica evidente a qualidade do serviço e a satisfação dos usuários. No entanto, focar na satisfação dos usuários dos serviços está cada vez mais complexo porque 
aqueles estão cada dia mais criteriosos (DINIZ; ROSADAS; MACEDO, 2006). Por isso, as expectativas dos clientes devem ser atendidas e superadas, principalmente quando se trata de instituição qu e forma pessoas, onde o grau de exigência e as críticas são intensas (FLORIANO et al., 2013).

Assim como nas demais organizações desse setor, a eficiência e eficácia dos serviços das instituições educacionais dependem da forma como lidam com o público, de modo a atender expectativas e gerar satisfação (SPANHOL; FIGUEIREDO NETO; LIMA-FILHO, 2010), respondendo com rapidez e flexibilidade às suas exigências e do ambiente (QUEIROZ et al., 2010). Diniz, Rosadas e Macedo (2006) entendem que o mínimo que a organização deve fazer é proporcionar atendimento adequado e manter a relação e a comunicação satisfatórias com os usuários.

Nesse contexto, ressalta-se Nadler (1994 apud PATINI; FILGUEIRA; FERNANDES, 2010), quando afirma que cabe ao gestor dirigir a organização de modo a alcançar a sua eficiência, entretanto esse resultado pode ser um tanto difícil, uma vez que nesse processo estão envolvidas questões comportamentais e de relacionamento dos indivíduos. Ademais, "[...] no processo de gestão universitária, a organização deve dispor de mecanismos para que os recursos estejam disponíveis no momento certo." (QUEIROZ et al., 2010, p. 6.). Desse modo, é preciso gerir os recursos essenciais para alcançar a qualidade dos serviços de forma que seja possível planejar e executar ações para evitar, minimizar ou, até mesmo, dirimir suas falhas (FARIA; BARUCHI, 2009).

Diante do exposto, entende-se a real necessidade das organizações de ensino superior implementarem a gestão inovadora, realizando mudanças executadas pelas pessoas, por meio de estratégias que permitam a prestação de um serviço de qualidade que atenda às necessidades dos usuários e o alcance dos resultados pretendidos, proporcionando competitividade à organização (QUEIROZ et al., 2010). Para tanto, “[...] é fundamental repensar a estrutura organizacional das universidades para adaptá-las a esses novos contextos [...] Esse quadro requer um novo modelo de organização e de gestão para atuar de modo eficaz nesse cenário.” (FREITAS JÚNIOR et al., 2015, p. 2). Torna-se um desafio constante realizar os devidos ajustes e tornar as estruturas mais modernas (PATINI; FILGUEIRA; FERNANDES, 2010).

Considerando a relevância das instituições de educação superior frente ao cenário atual, o que implica na necessidade de reorganização de suas estruturas com vistas à otimização da gestão dos serviços, convém compreender qual a relação entre as estruturas organizacionais das universidades e os serviços por elas oferecidos.

\subsection{Estrutura organizacional e a prestação de serviços de universidades}

Para Cury (2006), a estrutura de uma organização diz respeito à disposição de suas unidades, bem como as relações, decisões, responsabilidades e processos envolvidos. Assim, as organizações possuem estrutura organizacional, a qual precisa atender às necessidades e funcionar "[...] como ferramenta de controle, através da distribuição de cargos, das relações interpessoais, do planejamento das metas e dos objetivos." (COSTA; SOUZA; FELL, 2012, p. 60).

É por meio da estrutura organizacional, a ser definida conforme os objetivos e estratégias 
da organização, que os processos são implementados e os planos são atingidos (OLIVEIRA, 2010). Para Vieira e Vieira (2003), quando a estrutura de uma organização é dotada de pouco dinamismo e excessiva tradição, ela costuma desenvolver-se aquém dos setores mais ativos do mercado, tornando difícil a reestruturação.

A primeira reforma estrutural das universidades federais brasileiras ocorreu no fim da década de 60, quando o Conselho Federal de Educação aprovou a Lei 5.540, de 28 de novembro de 1968, fixando normas acerca da estrutura e organização daquelas instituições, atualizando-as para tentar torná-las menos burocráticas (VIEIRA; VIEIRA, 2004). A reforma de 1968 considerou o modelo elaborado pelo consultor Rudolph Acton e propôs uma adaptação das estruturas empresariais americanas às universidades brasileiras, sem levar em conta a conjuntura nacional (FERNANDES, 2014). Nesse sentido, autores com Oliven (1989 apud LOPES; BERNARDES, 2005) considera os modelos propostos uma mera importação dos estrangeiros, apesar de trazer algumas inovações, como por exemplo, o departamento como a menor unidade administrativa (FREITAS JÚNIOR et al., 2015).

Conforme Lopes e Bernardes (2005), posteriormente, a Lei $\mathrm{n}^{0} 5.540$ fora revogada pela Lei no 9.394 de 1996, a chamada Lei de Diretrizes e Bases da Educação Nacional (LDB), que deu origem a quatro novos modelos derivados dos anteriores. Os departamentos, como menor unidade administrativa, foram substituídos pelos cursos. Para Vieira e Vieira (2003), ao contrário do esperado, as universidades se tornaram ainda mais burocráticas, em virtude da complexidade imposta pelas inúmeras unidades administrativas que passaram a existir após as reformas (VIEIRA; VIEIRA, 2003).

Nesse caso, é compreensível que os órgãos públicos não consigam implementar mudanças radicais, estruturais e de gestão, em virtude de sua subordinação a leis e normas vigentes (PALÁCIOS, 2011; POLLITT, 2017). Lopes e Bernardes (2005) salientam ainda que a problemática da estruturação das instituições de ensino superior consiste na dificuldade de encontrar um modelo voltado às suas particularidades, as quais envolvem políticas e ideologias diversas que ocasionam diferenças, até mesmo no entendimento do que seja o projeto de universidade. Por esse motivo, as universidades brasileiras continuam na busca de um modelo ideal para o desenvolvimento de suas atividades com eficiência e eficácia.

Ressalta-se que nas IES do Brasil existe jogo político que por vezes prejudica a autonomia institucional, visto que os gestores tomam decisões, que podem ser ora centralizadas ou descentralizadas, na busca por tentar equilibrar os interesses dos envolvidos (PALÁCIOS, 2011). Assim, a questão da autonomia das instituições de ensino superior no Brasil vai muito além de quesitos meramente formais ou legais, mas envolve outros aspectos históricos, culturais, socioeconômicos que precisam ser analisados, além da estrutura organizacional. Desse modo, as IES públicas se destacam pela forte hierarquia que possuem, o que dificulta ainda mais os processos de decisão e comunicação e acabam por ressaltá-las frente ao atual cenário de transformações, principalmente no que se refere à formação e propagação do conhecimento e as relações dessas organizações com a sociedade (TRIGUEIRO, 2017).

Algumas organizações públicas, como hospitais e universidades (OSUPILE; MAKAMBE, 2021), têm se modernizado com atraso e as mais afetadas são justamente as universidades federais que costumam priorizar a burocratização administrativa e acadêmica de suas estruturas organizacionais (VIEIRA; VIEIRA, 2004). Desse modo, é imprescindível a inovação (DANIEL; LIMA; FERRARI DAMBROS, 2017; LEO; TELLO-GAMARRA, 2020; 
WITELL et al., 2017) e o processo de estruturação de tais organizações (COSTA; SOUZA; FEL, 2012), pois enquanto produtoras de conhecimento, devem definir estratégias que vão de encontro à quele cenário burocrático (VIEIRA; VIEIRA, 2003), uma vez que, quando o sistema educacional está envolvido na burocracia, morosidade e estrutura centralizada, a educação de qualidade não é alcançada (XAVIER, 1996).

Para tanto, Colenci Jr. et al. (2008) defendem que deve haver mudanças que permitam entender de que forma fatores como estrutura, organização, pessoas e tecnologias podem ser utilizados para melhorar resultados. Tais mudanças resultam da globalização (MOTTA, 1995), e tem feito, justamente, as organizações buscarem novas estruturas, processos e práticas administrativas e gerenciais (PIVA et al., 2005).

A atenção de identificar e antever ameaças e mudanças tem demonstrado relevância na obtenção de vantagem competitiva (JANTUNEN et al., 2018). Tal conduta é compreendida por Saul e Gebauer (2018) como uma capacidade organizacional. Parte-se para a busca de oportunidades e reconhecimento de ameaças para, então, desenvolver estruturas e procedimentos que auxiliem a tomada de decisão (TEECE, 2007).

Entendida como mudança da organização (MANTERE; SCHILDT; SILLINCE, 2012), as transformações são necessárias para que a empresa obtenha desempenho superior e mantenha a sua trajetória (LEITE; LUCENA, 2009). O estudo de mudança estratégica tem ocorrido por duas óticas que levam em consideração o papel do líder e do contexto na implementação das mudanças (MÜLLER; KUNISCH, 2018). Assim, a vertente da liderança tem atuação restrita e subordinada ao contexto da organização (PETTIGREW, 1987), já a outra busca identificar quão determinante é o dirigente na mudança (CHILD, 1972; JIANG et al., 2018).

Há outra corrente teórica que procura identificar a integração entre contexto e liderança nessa formulação (MÜLLER; KUNISCH, 2018). Mintzberg e Waters (1985) já haviam alertado para a necessidade de compreensão acerca da amplitude e complexidade dos fatores envolvidos no processo de elaboração de estratégias.

Assim, a mudança estratégica se relaciona às alterações das rotinas e estratégias de trabalho que influenciam a organização (HEROLD; FEDOR, 2008). As mudanças se relacionam também à revisão das prioridades e metas da empresa (GIOIA et al., 1994), compreensão compartilhada por Mantere, Schildt e Sillince (2012).

É oportuno destacar que mudança organizacional pode ser entendida como toda alteração de caráter relevante, que seja planejado e executado na organização, com o aval da gestão superior, e que envolva aspectos comportamentais, estruturais, tecnológicos e estratégicos (ARAÚJO, 2010). Contudo, há organizações que se submetem a processos de mudança estrutural sem passar por um concreto planejamento, quando a mudança deveria ser decidida com precaução e responsabilidade (PATINI; FILGUEIRA; FERNANDES, 2010), visto que "[...] para se obter um produto de qualidade nas organizações de ensino, são necessárias ações planejadas, sistemáticas e contínuas" (FARIA; BARUCHI, 2009, p. 3).

Nesse caso, “[...] as mudanças planejadas na estrutura organizacional são um dos meios mais eficazes para melhorar o desempenho do sistema empresarial" (OLIVEIRA, 2010, p. 64), com isso é preciso entender que a mudança deve ser um processo constante e continuar a 
implementar modelos ultrapassados representa uma contradição, visto que há uma cultura de caráter póstero e inovador das organizações em questão (VIEIRA; VIEIRA, 2003). No entanto, o pluralismo das universidades as torna um tipo de organizações resistentes à mudança, em virtude da disputa de poderes e interesses envolvidos (PALÁCIOS, 2011). Desse modo, deve-se ressaltar a importância de sensibilizar os condutores ou envolvidos no processo de transformação, pois mesmo que não tenha relação com o comportamento de pessoal, se não houver a conscientização não haverá como compreender o esforço necessário para a efetiva realização (ARAÚJO, 2010).

Ademais se ao longo do processo de mudança não forem considerados também os aspectos sociais e culturais dos agentes, os resultados alcançados não serão os mesmos pretendidos pela organização (PATINI; FILGUEIRA; FERNANDES, 2010), isso proporciona o controle sobre o desempenho e permite que as pessoas que nela atuam sejam responsáveis pelos resultados (COSTA; SOUZA; FELL, 2012).

\section{Procedimentos metodológicos}

A fim de entender ou interpretar ações de atores sociais, conforme definem Oliveira e Filgueira (2004), utilizou-se para fins desta pesquisa a abordagem qualitativa. Por concentrar-se em um caso específico e sua importância (SEVERINO, 2011), também é possível definir a pesquisa em questão como um estudo de caso. Para tanto, fora investigada a Universidade Federal Rural do Semi-Árido - UFERSA.

A UFERSA, instituição federal de ensino superior, está localizada no interior do Rio Grande do Norte e foi criada em 2006, quando foi transformada de Escola Superior de Agricultura de Mossoró (ESAM) para Universidade Federal. O campus sede está situado no município de Mossoró, e os demais campi distribuídos nas cidades de Caraúbas, Angicos e Pau dos Ferros .

A sua relevância histórica, social, acadêmica e científica, bem como as diversas mudanças sofridas ao longo do tempo, com destaque para a implementação do novo Estatuto em 2016, implicaram em diversas transformações, inclusive, na estrutura organizacional. Além da acessibilidade à instituição e por tudo isso, a realização da pesquisa na organização em questão tornou-se viável

A escolha dos respondentes na presente pesquisa foi substancial, de modo a obter informações para alcançar respostas ao problema que consistiu em compreender a relação entre a mudança de estrutura organizacional da UFERSA, motivada pela implementação do novo Estatuto e os serviços prestados. (DUARTE, 2002).

F oram escolhidos, para esta investigação, os seguintes sujeitos : ex-diretores interinos dos cinco centros localizados no campus sede, os quais assumiram mandato a partir da implementação do novo estatuto, quando da transformação dos departamentos em centros, até a realização das eleições para escolha dos diretores e vice-diretores para mandato de quatro anos; diretores e vice-diretores eleitos para mandato de quatro anos, dos cinco centros localizados no campus sede; ex-diretores interinos dos cinco centros localizados no campus sede que foram 
reconduzidos ao cargo após processo eleitoral; diretores e vice-diretores dos três centros multidisciplinares localizados nos campi universitários, criados a partir da implementação do novo Estatuto, sendo, automaticamente, os mesmos diretores e vice-diretores dos campi; servidores técnico-administrativos lotados nos cinco centros localizados no campus sede; servidores técnico-administrativos lotados nos três centros multidisciplinares, localizados nos campi universitários; servidores docentes lotados nos cinco centros do campus sede; servidores docentes lotados nos três centros multidisciplinares localizados nos campi universitários; discentes vinculados aos cinco centros d o campus sede; discentes vinculados aos três centros multidisciplinares dos campi universitários.

O critério para seleção dos investigados foi a acessibilidade, escolhendo-se os sujeitos disponíveis a participar da pesquisa, os quais detinham as informações para alcançar o propósito da investigação. $\mathrm{O}$ instrumento para coleta de dados foi o questionário com perguntas fechadas e abertas, totalizando dez instrumentos diferentes, enviados por e-mail aos pesquisados por meio da ferramenta eletrônica Google F ormulários, com o prazo de sete dias para resposta.

Nesse contexto, deve-se informar o número de respostas aos questionários, conforme a seguir especificado: para os questionários dos ex-diretores interinos dos centros que foram reconduzidos ao cargo após processo eleitoral, houve uma resposta; para os questionários dos diretores e vice-diretores de centro eleitos e que não haviam ocupado a função de diretor interino, houve uma resposta; para os questionários dos servidores técnico-administrativos lotados nos centros, houve três respostas; para os questionários dos servidores técnico-administrativos lotados nos campi, houve oito respostas; para os questionários dos docentes lotados nos centros houve dezenove respostas; para os questionários dos docentes lotados nos campi houve, dez respostas; para os questionários dos discentes vinculados aos centros do campus sede, houve sessenta e quatro respostas; para os questionários dos discentes vinculados aos centros multidisciplinares, houve cento e trinta e três respostas. Assim, totalizaram-se 239 respostas válidas. Insta mencionar que dos dez instrumentos enviados somente não houve resposta a dois deles, os quais eram direcionados aos ex-diretores interinos de centro e aos diretores e vice-diretores dos centros multidisciplinares.

É importante ressaltar que também fora necessário realizar uma pesquisa documental de arquivos públicos do tipo escrito, conforme Markoni e Lakatos (2010), a saber, documentos oficiais da universidade (portarias; estatuto antigo (versão 2013) e novo estatuto da UFERSA (versão 2016), e os organogramas propostos nos respectivos documentos), "interpretando-os e comparando-os, para torná-los utilizáveis” (MARKONI; LAKATOS, 2010, p. 50).

Após a coleta, os dados foram analisados de modo a organizá-los considerando a semelhança entre as respostas, comparando-as, e, em seguida, interpretando-as para a "[...] obtenção de um sentido mais amplo" (GIL, 2009, p. 178). Sendo necessário, por fim, fazer relação com o referencial teórico, conforme preconiza Severino (2011), examinando-os com base na análise de conteúdo (BARDIN, 2011), instrumentalizada com a codificação e categorização das informações obtidas nos questionários e documentos

\section{Resultados}

Esta seção revela a discussão dos resultados obtidos na pesquisa a fim de alcançar o 
objetivo pretendido. Inicialmente apresenta-se como ocorreu a mudança da estrutura organizacional implementada na UFERSA, em seguida, a avaliação dos serviços e da gestão de serviços da UFERSA, na visão dos pesquisados, por fim, a relação entre a mudança analisada e os serviços prestados na instituição.

\subsection{A mudança da estrutura organizacional}

No ano de 2016, a UFERSA enfrentou uma transformação significativa, quando fora implantado o novo Estatuto, em $1^{\circ}$ de setembro, que estava sendo discutido com toda comunidade acadêmica e aprovado, gradativamente, em reuniões do Conselho Universitário - CONSUNI. Contudo, para compreender as mudanças estruturais determinadas pelo documento, é importante explanar como era estabelecida a antiga estrutura da organização.

Segundo o art. $6^{\circ}$ do Estatuto da UFERSA (2013, p. 6) anteriormente em vigor, a UFERSA “[...] estrutura-se em Conselhos Superiores, Reitoria, Pró-Reitorias, Departamentos [...]. A Universidade contará, ainda, com órgãos suplementares que terão atribuições específicas definidas pelo seu Regimento Geral.”

Neste contexto, conforme o art. 33 do antigo Estatuto (2013, p. 25), a menor unidade da estrutura era formada pel os departamentos, “[...] para todos os efeitos de organização administrativa, didático-científica e de distribuição de pessoal e preferencialmente compreende disciplinas afins.", cuja administração deveria ser exercida pelo Chefe do Departamento e pela Assembleia Departamental.

Atualmente, o Estatuto e Regimento determinam a estrutura organizacional da UFERSA. Segundo art. 1\%, Parágrafo Único, do novo Estatuto (2016, p. 4), “[...] a UFERSA tem estrutura multicampi, distribuída na região do semiárido brasileiro, organizados em centros conforme critérios estabelecidos neste Estatuto.". Estando estruturada, segundo o art. $6^{\circ}$ (2016, p. 7), em: "Conselhos Superiores, Reitoria, Pró-Reitorias, Superintendências, centros e Departamentos Acadêmicos, com finalidades definidas e funções próprias de organização acadêmica". Ness e contexto, a implementação dos centros fora, por sua vez, a principal mudança na estrutura da universidade, estando assim definidos e distribuídos, conforme art. 61 do Estatuto (2016, p. 30): "[...] o Centro é a estrutura universitária, para todos os efeitos de organização administrativa, financeira, didático-científica e de distribuição de pessoal e compreende as grandes áreas de conhecimento",

Os atuais centros em funcionamento na universidade foram estabelecidos pela Portaria UFERSA/GAB n ${ }^{\text {o }}$ 0594/2016 de 01 de setembro de 2016, que teve por finalidade, "[...] transferir as competências de organização administrativa, financeira, didático-científica e lotação de pessoal dos departamentos para os centros", conforme seu art. $1^{\circ}$.

Desse modo, foram extintos os antigos departamentos da universidade, passando a funcionar os centros que, de acordo com o art. 62 do Estatuto da UFERSA (2016, p. 30), estão subdivididos em: Assembleia de Centro; Direção de Centro; Conselho de C entro; Assembleias Departamentais; Departamentos Acadêmicos; Colegiados de Cursos e Unidades Suplementares. Ness e ponto é necessário observar o artigo 68 do novo Estatuto (2016, p. 33) que indica que o departamento continua sendo " [...] a menor fração da estrutura universitária, para todos os 
efeitos de organização administrativa, didático-científica e de distribuição de pessoal e preferencialmente compreende disciplinas afins.", indo de encontro ao artigo 62 do mesmo Estatuto bem como ao organograma da universidade, que é possível observar que subordinados aos departamentos estão ainda os colegiados de cursos.

É importante ressaltar que até julho de 2017, os novos departamentos estavam em fase de concepção, e ainda não foram devidamente implantados. Além disso, suas funções e atribuições são estabelecidas no novo Regimento que deverá ser implementado no futuro próximo, visto que o documento em vigor está sendo submetido a alterações.

Ness e contexto, é possível perceber que a antiga estrutura organizacional da UFERSA ainda estava enquadrada em um dos modelos proposto pela Lei $\mathrm{n}^{\circ} 5.540$ de 1968, e o modelo atual, atende à Lei no 9.394, de 1996, conforme definem Lopes e Bernardes (2005). Assim, os departamentos como menor unidade deram lugar aos cursos.

Diante do exposto, é oportuno mencionar que, assim como preconizam Vieira e Vieira (2003), ao contrário do esperado, é possível que a universidade tenha se tornado mais burocrática em virtude da complexidade imposta pela nova unidade administrativa que passou a existir após a reforma. Desse modo, é possível observar, então, que a mudança estrutural ocorrida na universidade analisada não é inovadora, uma vez que o modelo utilizado é da década de 1990. Além do que já vem sendo seguido por outras universidades federais, reafirmando Vieira e Vieira (2003), de que fica evidente a defasagem das estruturas da maioria das universidades, ao longo do tempo, e que ess as instituições são contraditórias, quando deveriam agir no entorno da inovação, e passam a se caracterizar por suas estruturas antigas e burocráticas.

Outrossim, é oportuno frisar ainda Vieira e Vieira (2004) quando defendem que dentre as organizações públicas, as IFES são as mais afetadas e m relação à modernização de suas estruturas, que costumam priorizar a burocratização administrativa e acadêmica. Ness e caso, de acordo com Palácios (2011), é até compreensível que essas instituições não consigam implementar mudanças estruturais radicais e de gestão em virtude de sua subordinação a leis e normas vigentes.

\subsection{Os serviços prestados}

Os serviços ocorrem por meio de processos subjetivos (SPANHOL; FIGUEIREDO NETO; LIMA-FILHO, 2010), que devem atender às necessidades do usuário (CAVALCANTI; FONSECA, 2012). Por esses motivos considerou-se necessário investigar, o modo como os usuários avaliam os serviços oferecidos pela UFERSA, visto que a qualidade dos serviços de uma organização é essencial, entendimento que está em consonância com Santos (2014).

Os serviços da universidade analisada foram explicitamente bem avaliados por pouco mais de cem pesquisados, que os classificaram com conceitos que variam de "bons" (81 respondentes) e "muito bons" (9 respondentes), "ótimos" (10 respondentes) e "satisfatórios" (6 respondentes) a até "excelentes" (5 respondentes), principalmente pelo fato de atenderem às suas necessidades e expectativas. Por sua vez, houve investigados que não deram esse tipo de classificação aos serviços, porém registraram que estão satisfeitos . Outros respondentes afirmaram que os serviços da UFERSA atendem em parte as suas necessidades, ou deixam a desejar em 
algumas situações, sendo, por isso, classificados como "razoáveis" (10 respondentes); "medianos" (10 respondentes) ou "regulares" (18 respondentes), totalizando 38 pesquisados. Observase também respondentes que não definiram os serviços com esses conceitos de classificação, no entanto, demonstraram estar parcialmente insatisfeitos.

Houve ainda pesquisados que definiram o serviço prestado pela UFERSA como "ruins" (4 respondentes); "muito ruins" (9 respondentes) ou "péssimos" (3 respondentes) - totalizando 17 respondentes - por causarem completa insatisfação derivada das falhas existentes durante a execução. Ocorreu que outros investigados não classificaram os serviços daquela maneira, porém afirmaram estarem totalmente insatisfeitos pelos mesmos motivos.

Considerando as opiniões diversas, percebe-se, de fato, a subjetividade característica dos serviços, como preconizam Diniz, Rosadas e Macedo (2006), ao afirmarem que, via de regra, a percepção do serviço prestado depende de aspectos individuais dos usuários. No que tange a qualidade dos serviços, percebe-se como positivo o fato da UFERSA alcançar as expectativas dos usuários, cumprindo a sua finalidade, que deve ser de atender às necessidades do público com qualidade, em conformidade com os preceitos de Mezomo (1994). Contudo, é preciso ressaltar que não é suficiente atender às expectativas dos usuários, mas também superá-las, em consonância com a compreensão de Floriano et al. (2013). Ademais, considerando as críticas dos investigados, deve-se atentar para o fato de que há usuários pouco satisfeitos ou totalmente insatisfeitos, corroborando Diniz, Rosadas e Macedo (2006) que indicam que os usuários de serviços estão cada vez mais exigentes e por isso torna-se difícil satisfazê-los, principalmente quando se trata de organizações de formação de pessoas, onde há críticas e maior nível de exigência. Em complementação ao exposto, os relatos de alguns dos investigados são apresentados na figura 1:

Figura 1 - Avaliação dos serviços da UFERSA.

\begin{tabular}{|c|c|c|}
\hline \multicolumn{3}{|c|}{ Avaliação dos serviços da UFERSA } \\
\hline $\begin{array}{l}\text { Bons; Muito bons; Ótimos; } \\
\text { (Satisfatórios - atendem às } \\
\text { necessidades e expectativas). }\end{array}$ & $\begin{array}{l}\text { Razoáveis; Medianos; } \\
\text { Regulares (atendem em partes } \\
\text { às necessidades, ou deixam a } \\
\text { desejar em algumas situações). }\end{array}$ & $\begin{array}{l}\text { Ruins; Muito ruins; Péssimos } \\
\text { (completa } \\
\text { apresentam falhas durante a } \\
\text { execução). }\end{array}$ \\
\hline $\begin{array}{l}\text { "Até agora está atendendo } \\
\text { as minhas necessidades.” } \\
\text { (Discentemossoro10) } \\
\text { "Os serviços prestados estão a } \\
\text { contento, atendendo as minhas } \\
\text { expectativas como aluno.” } \\
\text { (Discentemossoro34) } \\
\text { "Os serviços prestados são de } \\
\text { qualidade.” (Docentemossoro4) } \\
\text { "Os serviços prestados pela } \\
\text { UFERSA em Caraúbas são } \\
\text { ótimos, de boa qualidade e } \\
\text { prestam um enorme serviço à } \\
\text { sociedade.” (Docentecaraubas3) }\end{array}$ & $\begin{array}{l}\text { "Necessita melhorar em alguns } \\
\text { setores." (Docentemossorol0) } \\
\text { "A qualidade dos serviços } \\
\text { varia de acordo com o setor." } \\
\text { (Docentemossoro15) } \\
\text { "O serviço é prestado de forma } \\
\text { razoável." (Tecnicocaraubas6) } \\
\text { "Às vezes deixam a desejar." } \\
\text { (Discentecampi14) } \\
\text { "Alguns setor excelentes e outros } \\
\text { péssimos" (Diretormossoro1) }\end{array}$ & $\begin{array}{l}\text { "Falta clareza nos serviços } \\
\text { oferecidos." (Discentecampi38) } \\
\text { "Lentos, burocráticos e mal } \\
\text { prestados." (Discentecampi21) } \\
\text { "Ainda são bastante falhos." } \\
\text { (Discentecampi26) } \\
\text { "Pobres, burocráticos, } \\
\text { d e s o r g a n i z a d o s." } \\
\text { (Discentemossoro24) }\end{array}$ \\
\hline
\end{tabular}

Neste contexto, é relevante ressaltar que as críticas dos usuários pesquisados aparecem com sugestões para melhorias e ajustes, principalmente e m relação ao atendimento ao público; 
desorganização ou pouca padronização dos processos; morosidade e dificuldade na comunicação. Salienta-se a importância da organização desenvolver e manter boa relação com seus usuários, atendendo e satisfazendo as suas necessidades (SPANHOL; FIGUEIREDO NETO; LIMA-FILHO, 2010) e promovendo práticas que estejam adequadas não somente à função de ensino, mas que responda às pressões da sociedade com rapidez e flexibilidade (QUEIROZ et al., 2010).

\subsubsection{A gestão de serviços}

No que se refere à gestão dos serviços da UFERSA, considerando os relatos dos investigados, especificamente dos diretores e servidores técnico-administrativos, é possível perceber que há certo desafio em virtude da existência dos inúmeros aspectos envolvidos no processo, o que tem exigido um serviço com nível de excelência, em consonância com Resende Júnior (2007). Por sua vez, os diretores elencaram como principais desafios da gestão a ausência de uma estrutura ideal para prestar serviços de qualidade, bem como a descentralização parcial de recursos, a qual dificulta a plena execução dos serviços.

É oportuno remeter ao entendimento de Faria e Baruchi (2009), sobre a questão da necessidade de gerir adequadamente os recursos que proporcionam qualidade aos serviços, devendo permitir que haja implementações de ações que reduzam os problemas das organizações. Ademais, cabe mencionar também Queiroz et al. (2010), qu e entendem que a gestão das IES deva ser um processo baseado na integração e equilíbrio de ambiente e elementos que impulsionem a organização a atingir seus objetivos.

Já os servidores técnico-administrativos, quando questionados sobre como gestores e funcionários estavam empenhados no processo de gestão, consideraram tal empenho uma questão complexa, e ainda mencionaram que falta maior participação dos servidores técnico-administrativos nas decisões. O número insuficiente de servidores também foi mencionado como fator que dificulta a prestação de serviços.

Na figura 2, apresentam-se algumas observações acerca dos principais desafios enfrentados na gestão de serviços na UFERSA, segundo os d iretores e servidores técnico-administrativos dos centros:

Figura 2 - A gestão dos serviços da UFERSA na visão dos diretores e servidores técnico-administrativos dos centros.

\begin{tabular}{|l|}
\hline Desafios enfrentados na gestão de serviços na UFERSA \\
\hline “Ainda falta maior participação nas decisões por parte dos técnicos.” (Tecnicomossoro2) \\
"Falta de estrutura para funcionamento, descentralização apenas parcial, de recursos.” (Diretormossoro1) \\
"Aqui no campus Angicos especificamente, ainda precária [a gestão de serviços], devido à baixa quantidade \\
de servidores técnicos administrativos." (Tecnicoangicos2)
\end{tabular}

Nesse contexto, percebe-se a necessidade de que todos, gestores e servidores, estejam empenhados no processo de gestão, assim como defendem Floriano et al. (2013), o que resulta na qualidade dos serviços (MENDONÇA; SELIG; SILVA, 2005). No entanto, deve-se compreender o fato da complexidade ao gerir a organização com vistas à eficiência, por ser uma 
tarefa que envolve outras pessoas, além do gestor, com comportamentos e relacionamentos distintos (PATINI; FILGUEIRA; FERNANDES, 2010).

\subsection{A mudança da estrutura organizacional e os serviços prestados}

Diante do propósito da investigação, buscou-se investigar de que forma os usuários avaliam a mudança de estrutura organizacional implementada na UFERSA e os serviços prestados após a implementação dos centros e qual a implicação no desempenho da UFERSA. Para tanto, insta ressaltar que foram considerados somente os pesquisados que vivenciaram a referida mudança, ou seja, aqueles que já estavam lotados ou vinculados às unidades acadêmicas e/ ou administrativas da UFERSA antes da implementação dos centros ocorrida em setembro de 2016.

Com relação à mudança da estrutura organizacional, doze dos investigados avaliaram da seguinte maneira: "boa" (8 respondentes); importante (2 respondentes) "ótima" (1 respondente); e "excelente" (1 respondente). Outros pesquisados não avaliaram com esses conceitos, porém, entendem que a mudança é positiva e necessária, tendo em vista o crescimento da universidade e o cenário de mudanças. Assim como define Motta (1995) e considerando também Piva et al. (2005), que defendem que as mudanças são resultado da globalização, que faz com que as instituições passem a buscar por novas estruturas, processos e práticas administrativas e gerenciais.

Em contrapartida, houve investigados que, até o momento da pesquisa, não notaram resultados com a mudança da estrutura organizacional ou entendem que a mesma não representa mudanças significativamente positivas. Nesse sentido, é oportuno ressaltar que se faz necessário que a mudança proporcione o entendimento de como fatores como estrutura, organização, pessoas e tecnologias podem ser utilizados para melhorar resultados, como já visto em Colenci Jr. et al. (2008). Ademais, as pessoas que são responsáveis por conduzir o processo de mudança devem estar envolvidas e compreender o que deve ser necessário para que a mudança ocorra de fato, assim como define Araújo (2010).

Destaca-se ainda as diversas críticas dos investigados quanto à forma como a mudança fora pensada ou mesmo executada na UFERSA. Para ess es pesquisados, o planejamento da mudança foi realizado de forma errada, ou a sua execução está ocorrendo em desconformidade ao que fora planejado, o que pode implicar, negativamente, nos serviços prestados. Nesse contexto, a figura 3 apresenta a percepção de alguns dos investigados quanto à relação entre a mudança da estrutura organizacional e os serviços prestados. 
Figura 3 - A mudança da estrutura organizacional e os serviços prestados.

\begin{tabular}{|c|c|c|}
\hline Positivamente (necessária) & Não perceberam mudanças & $\begin{array}{c}\text { Negativamente (planejada ou } \\
\text { executada com falhas) }\end{array}$ \\
\hline $\begin{array}{l}\text { "Vejo como um ponto positivo, } \\
\text { pois a universidade cresceu e a } \\
\text { implementação do novo estatuto é uma } \\
\text { atualização da realidade da UFERSA." } \\
\text { (Tecnicocampi3) } \\
\text { "Tem uma tendência a melhorar os } \\
\text { serviços. Era uma mudança necessária." } \\
\text { (Docentemossorol3) } \\
\text { "Creio que a nova estrutura } \\
\text { otimizará os serviços prestados pela } \\
\text { instituição.”(Tecnicocaraubas8) } \\
\text { "Achei a decisão importante. Se } \\
\text { realmente funcionar, só teremos } \\
\text { ganhos." (Discentecampi116) } \\
\text { "Maior agilidade nos serviços." } \\
\text { (discentecampi126) } \\
\text { "Os centros são a forma organizacional } \\
\text { da maioria das grandes universidades, } \\
\text { a UFERSA crescerá e essa estrutura } \\
\text { facilitará as ações." (Docentecampi1) }\end{array}$ & $\begin{array}{l}\text { "Até agora, na prática, não vi } \\
\text { mudança." (Tecnicocaraubas6) } \\
\text { "Acredito que isso não } \\
\text { mudará muita coisa haja vista } \\
\text { que os campi sempre serão } \\
\text { dependentes financeiramente } \\
\text { da Sede." (Tecnicocaraubas7) } \\
\text { "No que tange aos serviços } \\
\text { à sociedade essa alteração } \\
\text { não teve nenhum impacto } \\
\text { positivo até o momento. Porém } \\
\text { os serviços já prestados não } \\
\text { sofreram descontinuidade." } \\
\text { (Diretormossorol) } \\
\text { "Talvez não [houve } \\
\text { impacto], porque não vi } \\
\text { maiores mudanças, apenas } \\
\text { mudaram-se os nomes." } \\
\text { (Docentemossorol0) }\end{array}$ & $\begin{array}{l}\text { "A criação da proposta foi feita } \\
\text { de modo participativo, mas a } \\
\text { implantação da mesma está } \\
\text { ocorrendo de forma desordenada." } \\
\text { (Docenteangicos10) } \\
\text { "Realizada de forma } \\
\text { conturbada, mal planejada. } \\
\text { (Discentecampi20)" } \\
\text { "Mudança ainda pouco } \\
\text { divulgada para os campi e } \\
\text { com pouca implementação } \\
\text { na prática, até o momento." } \\
\text { (Tecnicopaudosferros1) } \\
\text { "Os impactos ainda são } \\
\text { negativos por conta da forma } \\
\text { desordenada de sua implantação." } \\
\text { (Docentecampi10) }\end{array}$ \\
\hline
\end{tabular}

Neste contexto, diversos respondentes de todas as categorias avaliaram como positiva a forma como o atual modelo organizacional implica ou pode implicar no desempenho da universidade. Na visão dessas pessoas, a nova estrutura proposta pelo novo modelo organizacional pode permitir maior descentralização e autonomia, o que pode gerar agilidade e eficiência na solução de demandas. Outros investigados também de todas categorias reconhecem que no momento não há implicação do modelo de estrutura no desempenho da instituição, contudo, para eles, bons resultados podem ser alcançados mediante a perfeita execução do modelo proposto. O rganização e controle, além de democratização e modernização de processos também foram elencados como pontos que, se vierem a existir, podem ser favoráveis ao desempenho da universidade. Ademais, houve alguns dos respondentes das categorias docentes, diretores e servidores técnico-administrativos que acreditam que a nova estrutura da universidade não reflete ou influencia negativamente no desempenho da organização, justamente pelo planejamento defeituoso ou falhas durante a implementação.

Apesar das críticas, deve-se atentar para o fato de que a maioria dos respondentes das categorias diretores, servidores técnico-administrativos e docentes avalia o modelo atual de estrutura organizacional como o que proporciona mais autonomia à universidade, se comparado ao anterior. Já a maioria dos discentes investigados acredita que os modelos de estrutura organizacional anterior e atual são indiferentes à autonomia que proporciona à universidade.

Diante do exposto, é relevante refletir sobre a temática da mudança organizacional. Em primeiro lugar, é perceptível o caráter pluralista da instituição analisada, considerando as inúmeras opiniões acerca da mudança implementada e seus desdobramentos. Em algumas falas é possível perceber também a disputa de poderes e interesses, bem como a resistência à mudança, características típicas das instituições de ensino superior, conforme abordado por Palácios 
(2011). Destaca-se também a observação de Lopes e Bernardes (2005) quando afirmam que o problema das estruturas das IES está relacionado às inúmeras particularidades envolvidas no processo, tais como políticas e ideologias distintas que geram diferentes pensamentos, o que prejudica até mesmo o entendimento do projeto de universidade.

Essas peculiaridades dificultam a autonomia da universidade, visto que a gestão deve estar sempre buscando equilibrar interesses de todos os envolvidos nos processos. Desse modo, nota-se que há ações mais centralizadas que outras, e que ainda existe a dificuldade em promover a descentralização, em virtude dos aspectos legais, formais e até mesmo culturais, corroborando Trigueiro (2017) e Palácios (2011). Tais aspectos podem permitir compreender a dificuldade que existe nos processos de decisão e comunicação da universidade analisada, entre outras dificuldades citadas no início, por vezes até prejudicando a sua relação com a sociedade, conforme entendimento de Trigueiro (2017).

Quanto às críticas ao processo, estas merecem atenção, uma vez que foi recorrente a expressividade de que houve sérias falhas no planejamento e execução da mudança. Sabe-se que apenas reflete no desempenho da organização se for efetivamente planejada, de acordo com Oliveira (2010), e pautada em ações sistemáticas e contínuas, conforme Faria e Baruchi (2009), e que segundo Queiroz et al. (2010) deve ocorrer por meio de processos, onde as adequações vão acontecendo diariamente, para cumprir objetivos e melhorar a interação com o ambiente. Também é importante que ao longo do processo, os aspectos sociais e culturais dos agentes sejam considerados, porque do contrário, os resultados pretendidos não serão alcançados (PATINI; FILGUEIRA; FERNANDES, 2010).

\section{Conclusão}

A pesquisa em questão teve como objetivo analisar a relação entre a mudança de estrutura organizacional da UFERSA motivada pela implementação do novo Estatuto e os serviços prestados. Constata-se que a problemática das estruturas organizacionais pouco modernas não é uma realidade somente da UFERSA, mas de outras universidades federais, haja vista que a última reforma de estruturação fora proposta há mais de vinte anos.

Quanto à mudança em si, pode-se observar que a criação dos centros implicou em mais uma unidade administrativa e não causou relevantes impactos na prestação de serviços da universidade, tendo em vista que estes não sofreram descontinuidade e mantiveram o mesmo nível de qualidade. Haja vista a pluralidade já bastante comentada do ambiente universitário observa -se a aceitação total ou parcial com boa avaliação da mudança, bem como a total reprovação da mesma. Torna-se relevante atentar ainda para as críticas quanto aos serviços prestados e a gestão de serviços, bem como à forma como fora planejada e implementada a mudança estudada. É importante perceber que a universidade está na busca de um modelo ideal para o desenvolvimento de suas atividades.

Observa-se que esta pesquisa contribui no desenvolvimento do campo de estudo da gestão pública ao revelar que o engajamento dos dirigentes para influenciar mudanças $n$ a atualização das normas deve compor o conjunto de competências necessárias para o exercício da função. Tendo em vista que a estrutura organizacional implementada em 2016, por meio do novo estatuto, data da Lei $\mathrm{n}^{\circ}$ 9.394, de 1996. Outro destaque é identificado no fato que a gestão 
pública está distante dos avanços acadêmicos da literatura de Administração Estratégica que preconiza o planejamento e implementação de mudanças como etapas que precisam estar alinhadas e integradas.

Diante do exposto, observa-se que o estudo em questão é relevante ao ampliar os conhecimentos acerca da temática analisada, colaborando, assim, para desenvolvimento da academia, principalmente porque as questões abordadas refletem diretamente no desenvolvimento das universidades e levam a uma reflexão crítica acerca da estruturação, organização, gestão, prestação de serviços e inovação nessas instituições. Para futuras investigações, recomenda-se que seja abordada a mesma questão de pesquisa, desta vez, quando os centros estiverem funcionando de fato. Para tanto, recomenda-se investigar também os membros do Conselho Universitário da UFERSA os quais foram responsáveis pela apreciação e aprovação da mudança da estrutura organizacional, a fim de entender qual é a sua percepção após a implementação da referida mudança. Ademais, tem-se como limitações da investigação a ausência de relatos do reitor e vice-reitor que conduziram a mudança e a falta da adoção de entrevistas individuais com os atores envolvidos que poderiam revelar nuances do fenômeno examinado.

\section{Referências}

AL-DAAJA, Y. Leadership and management of strategic change. SEA - Pratical Application of Science, n. 14, p. 237-245, 2017.

ARAÚJO, L. C . G. de. Organização, sistemas e métodos e as tecnologias de gestão organizacional. 4. ed. São Paulo: Atlas 2010. 334 p.

BARDIN, L. Análise de Conteúdo. São Paulo: Edições 70, 2011.

CAVALCANTI, W . M .; FONSECA, A . T . Gestão de serviços: a percepção do usuário quanto aos serviços prestados no atendimento ao público de uma cooperativa de crédito. Revista de Gestão e Tecnologia, v. 2, n. 2, p. 05-16, Jul/Dez 2012.

CHILD, J. Organizational Structure, Environment and Performance: the role of strategic choice. Sociology, v. 06, n. 01, p. 1-22, 1972.

COLENCI JÚNIOR et al. A Gestão Estratégica das Instituições de Ensino Superior: uma contribuição ao melhor desempenho no caso brasileiro. Anais... III Workshop de Pós-Graduação e Pesquisa- Centro Paula de Souza/ SP, 2008. p. 1 -9.

COSTA, M . C. F. da; SOUZA, Bruno Silvestre Silva de; FELL; André Felipe de Albuquerque. Um estudo da estrutura organizacional e as mudanças organizacionais: proposta de um novo modelo. Revista de Gestão e Tecnologia, v. 2, n. 1, p. 57-74, Jan/Jun 2012.

CURY, A . Organização e métodos uma visão holística. 8. ed. São Paulo: Atlas 2006. 600 p.

DANIEL, V. M.; LIMA, M. P.; FERRARI DAMBROS, Â. M. Innovation capabilities in 
services: a multi-cases approach. Academia Revista Latinoamericana de Administración, v. 30, n. 4, p. 490-507, 2017.

DINIZ, S. V; ROSADAS, L. A. S; MACEDO, M. A. S. Impacto da Qualidade em Serviços no Sucesso de Sites de Comércio Eletrônico. Anais... III SEGeT - Simpósio de Excelência em Gestão e Tecnologia, 3 , Resende, Rio de Janeiro, 2006. Disponível em: http://www.aedb.br/ seget/arquivos/artigos06/753 Artigo\%20Seget\%20TI.pdf Acesso em: 19 jun. 2017.

DUARTE, R. Pesquisa Qualitativa: reflexões sobre o trabalho de campo. Caderno de Pesquisas, n. 115, p 139-154, mar 2002. Disponível em: <http://www.scielo.br/pdf/cp/n115/a05n115. pdf >Acesso em: 19 jun. 2017.

ESTRADA, R. J . S . Os rumos do planejamento estratégico na universidade pública: um estudo de caso na Universidade Federal de Santa Maria. Tese (Doutorado em Engenharia de produção). Universidade Federal de Santa Catarina, Florianópolis. 219f, 2000.

FARIA, S. E.; BARUCHI, S. R. S. A qualidade nas instituições de ensino superior. The quality on High Education Institute. Anais... VI CONVIBRA Congresso Virtual Brasileiro de Administração, 2009. Disponível em: < http://www.convibra.com.br/2009/artigos/109 0.pdf $>$ Acesso em: 19 jun. 2017.

FERNANDES, L. T . Estrutura e desempenho organizacional: uma análise na Universidade Federal do Rio Grande do Norte. Dissertação (Mestrado em Administração). Universidade Federal do Rio Grande do Norte, natal. 132f, 2014.

FLORIANO, B . M . et al. A Prestação de Serviços nas Instituições de Ensino Superior: uma abordagem visando à qualidade no atendimento. Revista Ampla de Gestão Empresarial, v. 2, n. 2, p. 35-49, Mai 2013.

FREITAS JÚNIOR, O. de G . et al. Reestruturando o modelo de universidade pública brasileira para atender aos novos desafios gerenciais. Anais... CIGU, 2015. p. 1 -15.

GIANESI, I. G. N.; CORRÊA, H. L . Administração estratégica de serviços: operações para a satisfação do cliente. São Paulo: Atlas 2012. 233 p.

GIL, A. C. Métodos e técnicas de pesquisa social. 6. ed. São Paulo: Atlas, 2009.

GIOIA, D. A.; THOMAS, J. B.; CLARK, S. M. CHITTIPEDDI, K. Symbolism and strategic change in academia: the dyamics of sensemaking and influence. Organization Science, v. 05, p, 363-383, 1994.

HEROLD, D. M.; FEDOR, D. B. Change the way you lead change: leadership strategies that really work. Stanford University Press, 2008.

IOTTI NETO, L . Percepção da qualidade dos serviços prestados em uma instituição privada de ensino superior. Dissertação (Mestrado Profissionalizante em Engenharia). Universidade 
Federal do Rio Grande do Sul, Porto Alegre. 235f, 2004.

JANTUNEN, A.; TARKIAINEN, A.; CHARI, S.; OGHAZI, P. Dynamic Capabilities, Operational Changes, and Performance Outcomes in the Media Industry. Journal of Business Research, v. 89, p. 251-257, 2018.

JIANG, W.; WANG, L.; CHU, A.; MA, X. How Analyst Recommendation Change Influences Strategic Change: the moderating role of ceo power and board's informal hierarchy. Journal of Organizational Change Management, v. 31, n. 6, p. 1234-1248, 2018.

LEITE, Y. V. P.; LUCENA, E. de. A. Mudanças Estratégicas da Accor Hotels do Brasil. Revista Base (Administração e Contabilidade) da UNISINOS, v. 6, n. 2, p. 152-168, 2009.

LEO, R.; TELLO-GAMARRA, J. 'Drivers' da Inovação em Serviços: Proposição de um Modelo Teórico. Revista de Administração Mackenzie, v. 21, n. 3, p. 1-28, 2020.

LOPES, L. A. C ; BERNANRDES, F. R . Estruturas administrativas das universidades brasileiras. Anais... SEMEAD, 2005. p. 1 -13.

LOVELOCK C. ; WIRTZ, J. ; HEMZO, M. A . Marketing de serviços: pessoas, tecnologia e estratégia. 7. ed. São Paulo: Pearson 2011. 530 p.

MAINARDES, E. W.; DOMINGUES, M. J. C. S.; DESCHAMPS, M. Avaliação da qualidade nos serviços educacionais das instituições de ensino superior em Joinville, SC. Revista de Gestão, v. 16, n. 1, art. 2, p. 17-32, Jan/Mar 2009.

MANTERE, S.; SCHILDT, H. A.; SILLINCE, J. A. A. Reversal of Strategic Change. Academy of Management Journal, v. 55, n. 1, p. 172-196, 2012.

MARKONI, A. M.; LAKATOS, E. M. Técnicas de pesquisa. 7. ed. São Paulo: Atlas, 2010.

MENDONÇA, G . A . de A. ; $\quad$ SELIG, P. M .; SILVA, S. de C . Aplicações da qualidade em serviços educacionais. Anais... ENEGEP, 2005. p. 1615 -1620.

MEZOMO, J . C . Gestão da qualidade na escola: princípios básicos. São Paulo: J.C. Mezomo 1994. $207 \mathrm{p}$.

MINTZBERG, H.; WATERS, J. A. Of strategies, deliberate and emergent. Strategic Management Journal, v. 06, n. 03, p. 257-272, 1985.

MOTTA, R . A busca da competitividade nas empresas. Revista de Administração de Empresas, v. 35, n. 1, p. 12-16, Mar/Abr 1995.

OLIVEIRA, D. de P. R. de. Sistemas, organização e métodos. Uma abordagem gerencial. 19. ed. São Paulo: Pearson 2010. 484 p. 
OLIVEIRA, E. F. A.; FILGUEIRA, M. C. M. Primeiros passos na iniciação científica. v.1412. Mossoró: Coleção Mossoroense, série C, 2004.

OSUPILE, K.; MAKAMBE, U. The nexus between organisational culture and knowledge sharing in a government department in Botswana. The International Journal of Public Sector Management, v. 34, n. 2, p.118-136, 2021.

PALÁCIOS, F. A. C . Processo estratégico na criação e implantação da escola de artes, ciências e humanidades da USP: Esquema analítico e evidências empíricas. Tese (Doutorado em Administração). Universidade de São Paulo, São Paulo. 213f, 2011.

PATINI, A. de. C. G.; FILGUEIRA, J. C. G.; FERNANDES, V. Mudança na estrutura organizacional na visão dos trabalhadores em nível gerencial: um estudo de caso em uma empresa do setor químico. Revista Administração em Diálogo, v. 12, n. 3, p. 111-135, Set/ Out/ Nov/ Dez 2010.

PETTIGREW, A. M. Context and action in transformation of the firm. Journal of Management Studies, v. 24, n. 6, p. 649-670, 1987.

POLLITT, C. Public administration research since 1980: slipping away from the real world? International Journal of Public Sector Management, v. 30, n. 6-7, p. 555-565, 2017.

PORTARIA UFERSA/GAB Nº. 0594/2016 de 01 de setembro de 2016. Disponível em: $<$ https:// documentos.ufersa.edu.br/wp-content/uploads/sites/79/2016/01/Portaria-n $\%$ C2\%BA-0594-de01-de-setembro-de-2016.pdf >. Acesso em: 14 de jun. 2017.

PIVA, J. A. et al. Gestão da qualidade em serviços no ensino superior: uma reflexão sob a ótica dos graduandos em Administração. Revista Gestão e Conhecimento, v. 2, n. 1, p. 1-15, Jul/ Nov 2005.

QUEIROZ, F. C. B. P . Gestão Estratégica e Financeira das Instituições de Ensino Superior: um estudo de caso. Anais... XXX ENEGEP - Encontro Nacional de Engenharia De Produção, São Carlos, São Paulo, 2010. Disponível em: http://www.abepro.org.br/biblioteca/enegep2010 tn sto 122789 15511.pdf Acesso em: 19 jun. 2017.

RESENDE JÚNIOR, P . C . Gestão de serviços: uma abordagem da teoria das restrições. Anais... CONVIBRA, 2007. p. 1 -18.

SANTOS, G. S. dos. Avaliação da qualidade do serviço educacional numa instituição de ensino superior privada: a perspectiva de alunos de graduação em um estudo longitudinal. Dissertação (Mestrado Profissionalizante em Administração). Universidade Potiguar, Natal. 138f, 2014.

SAUL, C. J.; GEBAUER, H. Born Solution Providers - dynamic capabilities for providing solutions. Industrial Marketing Management, v. 73, p. 31-46, 2018. 
SEVERINO, A . J . Metodologia do trabalho científico. 23. ed. São Paulo: Cortez, 2011.

SILVA, A. M. da; PEREIRA, R . da S . Avaliação da qualidade dos serviços educacionais prestados por uma instituição de ensino superior (IES). Revista Administração: Ensino e Pesquisa, v. 13, n. 1, p. 111-144, Jan/Fev/Mar 2012.

SOUKI, G . Q. ; NETO, J . B . Desenvolvimento e Validação de uma Escala para Avaliação da Qualidade Percebida por Estudantes de Instituições de Ensino Médio. Anais... EnANPAD, 2007. p. 1 -16.

SOUKI, G. Q .; PEREIRA, C. A. Satisfação, Motivação e Comprometimento de Estudantes de Administração: Um Estudo Com Base nos Atributos de uma Instituição de Ensino Superior. Anais... EnANPAD, 2004. p. 1 -16.

SPANHOL, C. P. ; FIGUEREDO NETO, L. F. ; LIMA-FILHO, D. de O . Qualidade dos Serviços Educacionais: o caso de uma Instituição de Ensino Superior Privada. INGEPRO - Inovação, Gestão e Produção, v. 2, n. 12, p. 64-73, Dez 2010.

TEECE, D. J. Explicating Dynamic Capabilities: the nature and microfoundations of (sustainable) enterprise performance. Strategic Management Journal, v. 28, n. 13, p. 1319-1350, 2007.

TRIGUEIRO, M . G. S. Gestão da educação superior no Brasil. Disponível em: $<\underline{\text { http:// }}$ portal.mec.gov.br/sesu/arquivos/pdf/governo e gestafinal michelangelogiotto.pdf $>$. Acesso em: 07 jan. 2017.

UNIVERSIDADE FEDERAL RURAL DO SEMI-ÁRIDO. Estatuto. Mossoró, 2013. Disponível em: < https://documentos.ufersa.edu.br/estatuto/> Acesso em: 15 jul. 2017.

UNIVERSIDADE FEDERAL RURAL DO SEMI-ÁRIDO. Estatuto. Mossoró, 2016. Disponível em: $<$ https://documentos.ufersa.edu.br/estatuto/> Acesso em: 15 jul. 2017.

VIEIRA, E. F.; VIEIRA, M. M. F. Estrutura organizacional e gestão do desempenho nas universidades federais brasileiras. Revista de Administração Pública, v. 37, n. 4, p. 899-920, Jul/Ago 2003.

VIEIRA, E. F.; VIEIRA, M. M. F. Funcionalidade burocrática nas universidades federais: conflito em tempos de mudança. Revista de Administração Contemporânea, v. 8, n. 2, p. 181-200, Abr/Jun 2004.

XAVIER, A. C. da R. A gestão da qualidade e a excelência dos serviços educacionais: custos e benefícios de sua implantação. Disponível em: < http://www.ipea.gov.br/agencia/images/ stories/PDFs/TDs/td_0408.pdf>. Acesso em: 07 jan. 2017.

WITELL, L.; GEBAUER, H.; JAAKKOLA, E.; HAMMEDi, W.; PATRICIO, L.; PERKS, H. A bricolage perspective on service innovation. Journal of Business Research, v. 79, p. 290-298, 2017. 
